Max-Planck-Institut für demografische Forschung

Max Planck Institute for Demographic Research

Konrad-Zuse-Strasse 1 - D-18057 Rostock · GERMANY

Tel +49 (0) 3812081 - 0; Fax +49 (0) 3812081 - 202;

http://www.demogr.mpg.de

MPIDR WORKING PAPER WP 2007-004

JANUARY 2007

\title{
Pushing the limit: long-term trends in late fertility in Sweden
}

\author{
Francesco C. Billari (francesco.billari@unibocconi.it) \\ Hans-Peter Kohler (hpkohler@pop.upenn.edu) \\ Gunnar Andersson (andersson@ demogr.mpg.de) \\ Hans Lundström (hans.lundstrom@scb.se)
}

This working paper has been approved for release by: Gerda Ruth Neyer (neyer@ demogr.mpg.de) Deputy Head of the Laboratory of Contemporary European Fertility and Family Dynamics.

(C) Copyright is held by the authors.

Working papers of the Max Planck Institute for Demographic Research receive only limited review. Views or opinions expressed in working papers are attributable to the authors and do not necessarily reflect those of the Institute. 


\title{
Pushing the Limit: Long-term Trends in Late Fertility in Sweden
}

\author{
Francesco C. Billari \\ Hans-Peter Kohler \\ Hans Lundström* \\ January 12, 2007
}

Gunnar Andersson

\begin{abstract}
In this paper we discuss trends in the limits to late childbearing, their determinants and potential implications from an empirical long-term perspective. Although the high levels observed in non-contracepting populations have not been reached, fertility in Europe at ages $40+$ and $45+$ has increased substantially in recent years. This trend received considerable attention, especially in combination with the emergence of new reproductive technologies and often low levels of general fertility. Nevertheless, physiological studies agree on the fact that age limits to childbearing, at least for women, have not shifted to later ages. Our empirical analyses of highquality long-term data from Sweden document an increase in the absolute and relative number of births at ages 40+ and 45+, together with an increase in first birth occurrence-exposure rates at ages close to 40 . While extreme age at birth seems to move upwards, evidence for a rectangularization of the transition to motherhood is still weak.
\end{abstract}

Assessing and understanding the long-term trends in the age limits of childbearing is of crucial importance for evaluating contemporary below-replacement fertility and its consequences. Never before in history have European women borne their first children as late as at the beginning of the 21st century (Kohler et al. 2006; Prioux 2005). The entry into parenthood has been rapidly delayed also in many other developed countries, including the United States, where fertility postponement is particularly pronounced among non-Hispanic whites (Lesthaeghe and Neidert 2006; Martin et al. 2005). In light of these trends, Kohler, Billari and Ortega (2002) have argued that contemporary fertility trends in developed countries are characterized by a postponement transition that leads to rapid, persistent and generally irreversible delays in childbearing across a wide range of socioeconomic conditions. This postponement of childbearing implies an increasing fraction women

*Billari is Professor of Demography at the Institute of Quantitative Methods, Bocconi University, viale Isonzo 25, I20135 Milano, Italy, Director of the Carlo F. Dondena Centre for Research on Social Dynamics, and Fellow at the Innocenzo Gasparini Institute for Economic Research (IGIER); Email: francesco.billari@ unibocconi.it. Kohler is Professor of Sociology, University of Pennsylvania, Philadelphia, PA 19104-6299, USA; Email: hpkohler@pop.upenn.edu, Homepage: http://www.ssc.upenn.edu/ hpkohler. Andersson is Research Scientist at the Max Planck Institute for Demographic Research, Konrad-Zuse Str. 1, D-18057 Rostock, Germany, Email: andersson@ demogr.mpg.de. Lundström is Researcher at Statistics Sweden, Box 24 300, S-140 51 Stockholm, Sweden, Email: hans.lundstrom@ scb.se. The first two authors have contributed equally to this paper. Part of this research has been funded by the Max Planck Institute for Demographic Research. 
who attempt to become a mother at late ages, with potential concerns about age-related increases in infertility, an increased uncertainty about the ability to achieve desired fertility, and a reduced ability to accommodate to "shocks" to one's childbearing plans due to unanticipated union dissolution, delays in finding a suitable partner, miscarriages, or longer-than-expected waiting-times to pregnancy.

At the micro level, therefore, understanding the age patterns of fecundity, and the age-limits to conceive and have successful pregnancies is essential for answering questions such as "How late can you wait?" (Menken 1985), and to provide a guideline for individual's and couple's life-course decision-making about the timing of fertility and related behaviors. At the macro level, analyses of the trends in late fertility are of crucial importance in assessing whether declines in the pace of fertility postponement and associated reductions in tempo-distortions are likely to lead to increases in period fertility levels in low and lowest-low fertility countries with very late patterns of childbearing (Bongaarts 2002; Bongaarts and Feeney 1998). Despite the relevance of these aspects, however, insufficient knowledge exists about the long-term trends in late fertility, the propensity to have children at very advanced ages, and the potential effect of new assisted reproductive technologies on the ability to push the age limit of childbearing to increasingly later stages of the life course.

Limits to the delay of childbearing can be of social and biological nature. The perception of normative age limits to fertility postponement was frequent in the past, and continues being present at least in some contexts. Settersten and Hägestad (1996), for instance, using a survey on the population of Chicago's Metropolitan Area, find that $78.5 \%$ of the respondents perceive a normative "age deadline" for childbearing. In the Northern Italian region of Friuli-Venezia Giulia, Billari and Micheli (1999) find that about $90 \%$ of the respondents perceive an age deadline for childbearing. Average age deadlines range from 40.4 years to 41.4 years, not unlike similar estimates obtained by Toulemon and Leridon (1999) for France. These age deadlines correspond closely to frequently observed average ages at last birth in developed countries, and as observed by Toulemon and Leridon, they are close to early estimates of the biological limit to childbearing (Henry 1961). At the same time, there has been an increasing literature with books such as "What Every Woman Should Know About Fertility and Her Biological Clock” (Birrittieri 2004), or brochures on "Preserving your fertility" (Resolve 2005), that is clearly targeted at women who already have delayed — or anticipate to delay — childbearing to relatively late ages. This literature is extensive: Amazon.com ${ }^{1}$, for instance, lists 1,207 books under the subject "infertility", 450 of which were published after the year 2000. The demand for such information seems to indicate that current age deadlines for fertility are being challenged, and that biological limits are being pushed. This process, however, is not without obstacles. In a much noted book on "Creating a Life: Professional Women and the Quest for Children", Hewlett (2002) for instance describes the difficulties faced by educated women in having children at advanced ages, including job market concerns, mate-finding problems, subfecundity and infertility, and unrealized fertility desires resulting from 
delayed childbearing. A potential solution to ameliorate these challenges of delayed childbearing is offered by websites such as www.extendfertility.com ${ }^{2}$ that promise "Fertility - Freedom - Finally" through an egg freezing service that "offers [women] the opportunity to effectively slow down their biological clocks," allowing them to take better advantage of an "astounding number of opportunities" like obtaining advanced degrees, pursuing successful careers, and leading rich and demanding lives. A recent report prepared by RAND Europe also advocates the explicit incorporation of assisted reproductive technologies as part of the policy mix to increase fertility in Europe (Grant et al. 2006).

In the following discussion of trends in late childbearing, we will define very late fertility as childbearing at ages 40 and above, and latest-late fertility as childbearing at ages 45 and above. We also refer to ages 40 years and above as advanced childbearing ages, and to ages 45 years and above as very advanced childbearing ages. For selected countries, Table 1 shows that, after a decline during the 1970s and sometimes early 1980s along with the overall decline in fertility, very late and latest-late childbearing has been increasing in recent years both in terms of the total number of births, the age specific fertility rates at advanced and very advanced childbearing ages (ages 40 and above), and in terms of the fractions of all births and of the TFR respectively that occur above age 40 (for similar analyses, see Prioux 2005). Some of these changes have been substantial. In the U.S., for instance, age-specific fertility rates at ages above age 40 have more than doubled since 1980, while remaining at levels below those observed in several of the European countries in Table 1, and on average about .046 births or $2.3 \%$ of the TFR occur to women after age 40 (based on the sum of age-specific fertility rates above age 40). Moreover, the number of births in the U.S. to women aged 40 or older has increased more then fourfold since 1980, and $2.6 \%$ of all births in 2003 occurred to women aged 40 years and over.

While smaller in absolute numbers of births, the fraction of fertility and of all births occurring to women above age 40 is substantially larger in some European countries than it is in the U.S. Sweden, for instance, exhibits higher age-specific fertility rates at ages 40-44 in Table 1, with 9.6 annual births per 1000 women aged 40-44 years, and the fraction of the TFR that occurs above age 40 is close to close to $3 \%$ - corresponding to about .05 births after age 40 for each woman. The fraction of the TFR occurring after age 40 exceeds $3 \%$ in Italy and Spain, with these higher fractions in Italy and Spain due to lower fertility rates at younger ages rather than higher fertility rates above age 40 . Italy exhibits the highest fraction of births - 3.9\% - that occur to women aged 40 years and over. Despite these recent increases in late and latest-late fertility in the countries in Table 1, however, the age-specific fertility rates at ages above age 40 in 2002/03 are not high compared to the rates observed earlier in the 20th century or prior to the demographic transition. In Sweden around 1860, for instance, age-specific fertility rates were around 127 births per thousand women aged 40-44 and 20 per 1,000 women aged 45-49, implying that on average around .7 births_-or about $16 \%$ of the TFR_occurred to woman after age 40 (Statistics Sweden 1999). More recently, the post-WWII peak in the age-specific fertility rate at advanced ages in the U.S. 
occurred during 1956-57, with 16.3 births per 1,000 women aged 40-44 and 1.1 per 1,000 women aged 45-49 (NCHS 1997), a rate similar to that observed around 1970 in Italy and the Netherlands. During the peak of the baby boom in the U.S., therefore, about $2.3 \%$ of the TFR occurred above age 40 , or about .09 births per woman after age 40 in the 1957 synthetic cohort.

Across all countries in Table 1, the recent increase in the number of births to women aged 40 and older is substantially larger than the increase in age-specific fertility rates. The increase in the number of births to older women thus results in part from an increase in the fraction of women in childbearing ages who are above 40 . For instance, the fraction of women aged 40 years and older among women 15-49 years old has increased more than 50\% since 1980 in the U.S., and between 23-40\% in Sweden, Denmark and the Netherlands; somewhat smaller increases have occurred in Italy and Spain during the 1990s. A substantial part of the increase in the number of births to women above age 40 is therefore due to compositional age-structure changes among women in childbearing ages. In addition, even controlling for these age structure effects, the recent increase in age specific fertility rates above age 40 is in part compositional and can not fully be attributed to rising probabilities of conception or successful pregnancy at advanced childbearing ages. ${ }^{3}$ In particular, the age-specific fertility rates above age 40 in Table 1 are potentially affected by a shift in the parity distribution of women at advanced childbearing ages. Most important in this context is the increase at ages 40 and above of childless women or women at parity one who delayed fertility and intend to have a (additional) child at advanced ages. For instance, an increase in the fraction of women who are still childless at age 40 can result in an increase in age-specific fertility rate above age 40 - even if the probability of having a first child for women who are childless at age 40 is constant. In many countries such an increase in the proportion of women who are childless has occurred in recent years (see Table 2 for selected countries). In the United States, for instance, the proportion of childless or primiparous women at ages 40-44 has increased by 74-80\% during 1980-2000, and to the extent that this trend is due to postponed fertility rather than increases in desired childlessness or single-child families, it is likely to have contributed to the increase of age specific fertility rates above age 40. In the broader sense, this shift in the parity distribution reflects the changing birth-order composition of late and latest-late fertility (see also Prioux 2005; Toulemon 2005). In natural fertility populations, as well as during periods of high fertility, childbearing at advanced and very advanced ages was primarily due to births occurring to relatively fecund couples. In contemporary low fertility contexts, late and latest-late childbearing occurs increasingly at low parities-first or second children - and presumably to couples/women who are at the lower end of the fecundity distribution. In Sweden, for instance, more than $50 \%$ of all births to women aged 40-44 years old were first or second children, up from around $37 \%$ in the late 1960s; similarly, in the U.S. about $50 \%$ of births to women aged 40-44 were first and second children in 2002. ${ }^{4}$ This reversal of the parity composition of women who engage in childbearing at late and latest-late ages is likely to be a key factor contributing to the scientific and popular concerns about the consequences of delayed childbearing since failures to achieve fertility desires 
Table 1: Trends in fertility at advanced and very advanced childbearing ages

\begin{tabular}{|c|c|c|c|c|c|c|c|c|c|c|}
\hline \multirow[b]{2}{*}{ Year } & \multirow[b]{2}{*}{ TFR } & \multicolumn{3}{|c|}{ number of births } & \multirow{2}{*}{$\begin{array}{l}\text { fraction of } \\
\text { all births } \\
\text { occurring } \\
\text { to women } \\
\text { aged } 40+\end{array}$} & \multicolumn{2}{|c|}{ ASFR } & \multirow{2}{*}{$\begin{array}{c}\text { sum of } \\
\text { ASFRs } \\
\text { above } \\
\text { age } 40\end{array}$} & \multirow{2}{*}{$\begin{array}{c}\text { fraction } \\
\text { of TFR } \\
\text { above } \\
\text { age } 40\end{array}$} & \multirow{2}{*}{$\begin{array}{c}\text { fraction } \\
\text { aged } 40- \\
49 \text { among } \\
\text { women } \\
15-49\end{array}$} \\
\hline & & total & $\begin{array}{c}\text { age } \\
40-44\end{array}$ & $\begin{array}{l}\text { age } \\
45+\end{array}$ & & $\begin{array}{c}\text { age } \\
40-44\end{array}$ & $\begin{array}{l}\text { age } \\
45+\end{array}$ & & & \\
\hline \multicolumn{11}{|c|}{ United States } \\
\hline 1970 & 2.48 & $3,731,386$ & 49,952 & 2,146 & $1.4 \%$ & 8.1 & 0.1 & 40.8 & $1.6 \%$ & $25.4 \%$ \\
\hline 1980 & 1.84 & $3,612,258$ & 23,090 & 1,200 & $0.7 \%$ & 3.9 & 0.2 & 20.5 & $1.1 \%$ & $19.8 \%$ \\
\hline 1990 & 2.08 & $4,158,212$ & 48,607 & 1,638 & $1.2 \%$ & 5.5 & 0.2 & 28.5 & $1.4 \%$ & $24.4 \%$ \\
\hline 2000 & 2.06 & $4,058,814$ & 90,013 & 4,604 & $2.3 \%$ & 8.0 & 0.5 & 42.5 & $2.1 \%$ & $30.1 \%$ \\
\hline 2003 & 2.04 & $4,089,950$ & 101,005 & 5,845 & $2.6 \%$ & 8.7 & 0.5 & 46.0 & $2.3 \%$ & $31.1 \%$ \\
\hline \multicolumn{11}{|c|}{ Sweden } \\
\hline 1970 & 1.92 & 110,131 & 1,446 & 103 & $1.4 \%$ & 6.2 & 0.4 & 33.1 & $1.7 \%$ & $27.3 \%$ \\
\hline 1980 & 1.68 & 97,046 & 987 & 31 & $1.0 \%$ & 4.2 & 0.2 & 21.7 & $1.3 \%$ & $23.6 \%$ \\
\hline 1990 & 2.13 & 123,923 & 2,260 & 70 & $1.9 \%$ & 7.1 & 0.2 & 36.7 & $1.7 \%$ & $30.0 \%$ \\
\hline 2000 & 1.54 & 90,432 & 2,203 & 101 & $2.5 \%$ & 7.7 & 0.3 & 40.3 & $2.6 \%$ & $29.1 \%$ \\
\hline 2003 & 1.71 & 99,151 & 2,770 & 117 & $2.9 \%$ & 9.6 & 0.4 & 50.0 & $2.9 \%$ & $29.0 \%$ \\
\hline \multicolumn{11}{|c|}{ Denmark } \\
\hline 1970 & 1.99 & 70,791 & 774 & 46 & $1.2 \%$ & 5.4 & 0.3 & 28.4 & $1.4 \%$ & $25.9 \%$ \\
\hline 1980 & 1.55 & 57,288 & 367 & 17 & $0.7 \%$ & 2.5 & 0.1 & 12.8 & $0.8 \%$ & $23.2 \%$ \\
\hline 1990 & 1.67 & 63,431 & 747 & 29 & $1.2 \%$ & 3.9 & 0.2 & 20.2 & $1.2 \%$ & $28.9 \%$ \\
\hline 2000 & 1.77 & 67,080 & 918 & 15 & $1.4 \%$ & 6.6 & 0.2 & 34.0 & $1.9 \%$ & $29.1 \%$ \\
\hline 2003 & 1.76 & 64,679 & 1,460 & 56 & $2.3 \%$ & 7.5 & 0.3 & 39.1 & $2.2 \%$ & $30.0 \%$ \\
\hline \multicolumn{11}{|c|}{ France } \\
\hline 1970 & 2.47 & 847,565 & 18,795 & 1,311 & $2.4 \%$ & 11.4 & 0.8 & 60.8 & $2.5 \%$ & $27.8 \%$ \\
\hline 1980 & 1.95 & 800,223 & 6,600 & 486 & $0.9 \%$ & 4.5 & 0.3 & 24.0 & $1.2 \%$ & $23.8 \%$ \\
\hline 1990 & 1.78 & 762,292 & 12,481 & 500 & $1.7 \%$ & 5.8 & 0.3 & 30.6 & $1.7 \%$ & $24.9 \%$ \\
\hline 2000 & 1.88 & 774,680 & 18,723 & 676 & $2.5 \%$ & 8.7 & 0.3 & 45.1 & $2.4 \%$ & $29.6 \%$ \\
\hline 2002 & 1.88 & 761,539 & 19,889 & 811 & $2.7 \%$ & 9.1 & 0.4 & 47.4 & $2.5 \%$ & $29.8 \%$ \\
\hline \multicolumn{11}{|c|}{ Netherlands } \\
\hline 1970 & 2.57 & 238,882 & 5,321 & 441 & $2.4 \%$ & 14.0 & 1.2 & 75.9 & $3.0 \%$ & $24.7 \%$ \\
\hline 1980 & 1.60 & 181,242 & 1,381 & 120 & $0.8 \%$ & 3.4 & 0.4 & 18.9 & $1.2 \%$ & $21.7 \%$ \\
\hline 1990 & 1.62 & 197,629 & 2,171 & 226 & $1.2 \%$ & 3.8 & 0.5 & 21.4 & $1.3 \%$ & $25.8 \%$ \\
\hline 2000 & 1.72 & 206,598 & 4,013 & 122 & $2.0 \%$ & 6.5 & 0.2 & 33.5 & $1.9 \%$ & $29.5 \%$ \\
\hline 2002 & 1.73 & 202,083 & 4,353 & 147 & $2.2 \%$ & 6.8 & 0.3 & 35.4 & $2.0 \%$ & $30.3 \%$ \\
\hline \multicolumn{11}{|c|}{ Italy } \\
\hline 1970 & 2.43 & 900,971 & 29,946 & 2,243 & $3.6 \%$ & 15.8 & 1.2 & 85.2 & $3.5 \%$ & $28.4 \%$ \\
\hline 1980 & 1.64 & 640,356 & 12,217 & 867 & $2.0 \%$ & 6.3 & 0.5 & 33.9 & $2.1 \%$ & $27.4 \%$ \\
\hline 1990 & 1.33 & 569,246 & 10,679 & 415 & $1.9 \%$ & 5.4 & 0.3 & 28.0 & $2.1 \%$ & $26.2 \%$ \\
\hline 2000 & 1.24 & 543,114 & 15,511 & 915 & $3.0 \%$ & 7.5 & 0.4 & 39.7 & $3.2 \%$ & $27.9 \%$ \\
\hline 2003 & 1.29 & 524,742 & 19,585 & 892 & $3.9 \%$ & 9.2 & 0.5 & 48.3 & $3.8 \%$ & $29.8 \%$ \\
\hline \multicolumn{11}{|c|}{ Spain } \\
\hline 1970 & 2.88 & $\mathrm{n} / \mathrm{a}$ & $\mathrm{n} / \mathrm{a}$ & $\mathrm{n} / \mathrm{a}$ & $\mathrm{n} / \mathrm{a}$ & 26.1 & 3.5 & 148.0 & $5.1 \%$ & $27.1 \%$ \\
\hline 1980 & 2.22 & 570,547 & 15,134 & 1,675 & $2.9 \%$ & 14.8 & 1.4 & 80.9 & $3.6 \%$ & $25.2 \%$ \\
\hline 1990 & 1.36 & 401,272 & 7,094 & 487 & $1.9 \%$ & 5.9 & 0.4 & 31.4 & $2.3 \%$ & $23.7 \%$ \\
\hline 2000 & 1.24 & 397,530 & 9,733 & 430 & $2.6 \%$ & 6.6 & 0.3 & 34.6 & $2.8 \%$ & $26.0 \%$ \\
\hline 2002 & 1.27 & 418,725 & 11,751 & 560 & $2.9 \%$ & 7.6 & 0.4 & 40.0 & $3.1 \%$ & $27.0 \%$ \\
\hline
\end{tabular}

ASFR $=$ age specific fertility rate, per thousand. Sources: U.S.: Martin et al. (2005), and US Census Bureau (www.census.gov, accessed Feb 12, 2005). For European Countries: Eurostat (http://epp.eurostat.cec.eu.int, accessed Feb 12, 2006), ISTAT (http://demo.istat.it, accessed Oct 4, 2006), and Council of Europe (2004). 
Table 2: Parity distribution of women at advanced childbearing ages

\begin{tabular}{lllll}
\hline & & \multicolumn{3}{c}{ Fraction of women at } \\
\cline { 3 - 5 } & year & parity 0 & parity 1 & parity 2 \\
\hline United States & 1970 & 0.11 & 0.11 & 0.23 \\
(women aged 40-44) & 1980 & 0.09 & 0.11 & 0.25 \\
& 1990 & 0.14 & 0.17 & 0.35 \\
& 2000 & 0.16 & 0.19 & 0.34 \\
Sweden & 1970 & 0.15 & 0.20 & 0.34 \\
(women aged 40) & 1980 & 0.12 & 0.16 & 0.42 \\
& 1990 & 0.12 & 0.16 & 0.45 \\
Netherlands & 1999 & 0.15 & 0.14 & 0.41 \\
(women aged 40) & 1980 & 0.12 & 0.10 & 0.42 \\
& 1990 & 0.15 & 0.15 & 0.47 \\
& 1998 & 0.18 & 0.15 & 0.42 \\
\hline
\end{tabular}

Source: NCHS (1999) for United States; Kohler and Ortega (2002) for Sweden and the Netherlands

at low parities — and particular a failure to have at least one child — are likely to have significantly larger implications on individual's well-being than the widespread over- or undershooting desired fertility at higher parities (Kohler et al. 2005; Quesnel-Vallée and Morgan 2003).

In summary, the evidence reported above shows that the much noticed increase in the number of births and age-specific fertility rates above age 40 results, at least in part, from compositional factors - age distribution and parity composition - in addition to the changes in the behavioral, biological and technological aspects that affect the probability of giving birth conditional on a woman's age and parity. The distinction between compositional factors and factors related to the probability of giving birth conditional on age and parity is essential for interpreting trends in late childbearing and the potential well-being implications of unrealized fertility desires. However, so far, this aspect has been surprisingly absent in many discussions that point to the increased number of births at advanced ages (exceptions include Prioux 2005; Toulemon 2005). Moreover, studies of late and latest-late fertility in many countries are hampered by the fact that high ages at birth may be reported with error, and that official statistics often report births at very advanced ages in an open ended age category, usually 45 years and older-a practice that the U.S. Census Bureau has adjusted only recently in 1997 by shifting the open-ended interval to 50+ years (Martin et al. 2005).

The goal of this paper is to overcome the limitations of existing studies concerning late and latest-late fertility, and to identify trends and determinants of childbearing at advanced ages (ages $40+$ years). In our analyses, we therefore utilize Swedish register data that are of high quality, 
cover a long time period, and allow us to calculate conventional age-specific fertility rates (rates of the second kind) as well as occurrence-exposure rates (rates of the first kind) that eliminate the influences of shifts in the parity distribution. Before embarking on these statistical analyses, however, we review the literature on physiological factors that are relevant for understanding the empirical patterns, and we reflect on the potential contributions of recent innovations in assistant reproductive technologies in facilitating further delays of fertility towards advanced and very advanced childbearing ages.

\section{Physiological factors and late fertility}

Menopause is the uppermost limit for the reproductive life-span of women. While there have been cases of post-menopausal fertility due to assisted reproductive technologies (ART), including most recently a 62 year old Californian woman who gave birth to her 12th child after in vitro fertilization (IVF) treatment (MSNBC, Feb 21, 2006), the onset of women's permanent sterility usually precedes menopause by some years (te Velde et al. 1998). More specifically, age at menopause is on average about 50-51 years in Western countries, and shows a remarkable variation between women from 40 to 60 years that partially depends on a woman's contraceptive use and parity (Kaufert et al. 1987; Stanford et al. 1987; van Zonneveld et al. 2001). There seems to be no evidence for an increase in the age at menopause in recent years that parallels increases in longevity and would be consistent with a "rescaling" of the life-course in response to prolonged life expectancies (Lee and Goldstein 2003; Leridon 2004), and recent studies have that about $85 \%$ of the variability in the age at menopause is related to genetic influences (de Bruin et al. 2001).

The ability of a woman to start a pregnancy that ends in a live birth declines and ends several years before reaching the menopause, and this finding is supported by studies of populations not using contraception. Bongaarts (1983), for instance, reports that the median age of women at last birth is fairly stable around 40-41 years in natural fertility populations across different historical settings, marking an end of reproduction several years prior to menopause. Leridon (2004) estimates that in non-contracepting populations the mean age for three markers of women's transition into post-reproductive life are 41.2 years for the delivery of the last birth, 44.7 years for the onset of sterility, and 50.5 years for menopause.

Fecundability-i.e., the probability of conceiving within one month of unprotected sexual intercourse- has been shown to decline with age, both for men and for women (e.g., Auger and Jouannet 2005; Dunson et al. 2002; Gougeon 2005; Larsen and Vaupel 1993; Leridon 2004; Menken 1985; Skakkebæk et al. 2006), and biological aging has a strong impact on sterility especially above age 35 (e.g., Leridon 2005; Menken et al. 1986). Table 3, reports some frequently cited, albeit not uncontroversial, estimates on sterility by age. A possible sign of decreasing reproductive health associated with delayed childbearing is the rising demand for infertility treatment by means of assisted reproductive technologies (ART), including intracytoplasmatic sperm injection 
Table 3: Estimates of couples definitely sterile (inability to have a live birth) by woman's age (in percent)

\begin{tabular}{ccccccc}
\hline Age & $\begin{array}{c}\text { Vincent } \\
(1950)\end{array}$ & $\begin{array}{c}\text { Henry } \\
(1953) \\
\text { (England) }\end{array}$ & $\begin{array}{c}\text { Henry } \\
(1953) \\
\text { (Norway) }\end{array}$ & $\begin{array}{c}\text { Leridon } \\
(1977)\end{array}$ & $\begin{array}{c}\text { Trussell \& } \\
\text { Wilson } \\
(1985)\end{array}$ & $\begin{array}{c}\text { Menken \& } \\
\text { Larsen } \\
(1986)\end{array}$ \\
\hline 20 & 4 & 3.5 & 3.5 & 3 & & 4 \\
25 & 6 & 6 & 5 & 6 & 6 & 7 \\
30 & 10 & 11 & 8 & 10 & 11 & 12 \\
35 & 17 & 19 & 13 & 17 & 16 & 22 \\
40 & 37 & 33 & 24 & 29 & 24 & 46 \\
45 & 75 & 58 & 50 & 50 & 58 & \\
\hline
\end{tabular}

Source: This table is adapted from Leridon (2005). Notes: The estimates for Menken and Larsen (1986) are averaged across the seven studied populations, with interpolation to obtain estimates at exact ages. All estimates are obtained from natural fertility population or pre-transition populations, with the exception of Menken and Larsen (1986) that is based on XXth century populations.

(ICSI), in vitro fertilization (IVF), gamete intrafallopian transfer (GIFT) and zygote intrafallopian transfer (GIFT). ${ }^{5}$ The number of ART cycles performed in the United States, which do not include insemination according to the CDC (Center for Disease Control and Prevention) definition, has almost doubled from 64,810 cycles (.9 per 1000 women aged 15-49) in 1996 to 122,872 (1.7 per 1000 women aged 15-49) in 2003 (CDC 2005). The number of live birth deliveries resulting from ART has increased from 14,507 in 1996 to 35,785 (+147\%), and the number of infants born as a result of ART rose from 20,480 in 1996 to 48,756 (+138\%). In 2003, therefore, about 1.2\% of children born in the U.S. were conceived using ART, as compared to .5\% in 1996. ART utilization, however, differs substantially across countries. In Denmark, for instance, where ART treatments are generally covered by public health insurance, more than $4.2 \%$ of children during 2002-2004 were born after assisted reproduction. In 2002, this contribution of ART to overall fertility was achieved using 11,311 ART cycles, or about 9 cycles per 1,000 women aged 15-49 years old (Andersen and Erb 2006). In addition to these ART cycles, 9,526 insemination cycles were performed during 2002, resulting in a total of 17 ART and insemination cycles per 1,000 Danish women aged 15-49 years old. This represents the highest ART utilization in Europe, and counting also foreign adoptions and children conceived through inseminations, more than $7 \%$ of all Danish children born in 2002 were not "naturally conceived" (Andersen and Erb 2006).

Several reasons have been put forth to explain this decline in fecundability with a woman's age (e.g., see Gougeon 2005). The variability of the length of menstrual cycles increases with age, and this makes it more difficult for a couple to achieve conception, and may be a sign of predisposition to fetal problems (Billari and Rosina 2001; Spira et al. 1993). The difficulty of predicting this pattern could explain some of the surprisingly high female sterility and infecundity 
at older ages (Rahman and Menken 1993). In addition, sexual activity generally declines both with age and, usually, with the length of a given union (Brewis and Meyer 2005; Weinstein et al. 1993). Until recently, however, it has not been possible to distinguish the effect of this changing level of sexual activity from the effect of age on fecundity. Colombo and Masarotto (2000) have overcome this limitation trough the combination of appropriate menstrual and intercourse diary data that allows the inference of daily fecundability (see also Rizzi et al. 2005). Using such data, Dunson et al. (2002) have also shown that women's fecundability begins to decline in the late 20s with substantial decreases by the late 30 s.

A study on natural fertility populations showed that declining fecundity with maternal age is primarily a result of aging at the level of the ovaries (O'Connor et al. 1998). In particular, in the peri-menopausal years, which are of key interest when looking at the possibilities of postponing childbearing, declining fecundity is a function of both declining fecundability and increasing risk of fetal loss (Wilcox et al. 1988), much of which is due to chromosomal abnormalities. In addition, Andersen et al. (2000) found in a longitudinal population-based register study in Denmark that maternal age at conception is a strong and independent risk factor for fetal death, independently of reproductive history, and they conclude that the general chances of successful pregnancies in women aged 40 and over are poor. Nevertheless, there is also some evidence that the obstacles to late fertility are diminishing even in the absence of fertility treatments. In a Canadian medical database embracing the period 1961-1993, for instance, fetal death rates substantially decreased over time, although they remained significantly higher for women aged 40 and over (Fretts et al. 1995). Leridon's (2005) estimates of infertility by age also show that more women than previously thought may still be able to conceive at ages between 30 and 45 years, as many as $83 \%$ at age 40 , but that many of women in advanced childbearing ages will not be able to have a live birth due to miscarriage probabilities reaching $20 \%$ at age $37,30 \%$ at age 44 and $40 \%$ at age 48 years. In ART using the woman's own embryos, the percent of live births per cycles also declines strongly with age, starting in the mid 30s from about $40 \%$ to below $5 \%$ for women in the early $40 \mathrm{~s}$; in contrast, the high success rate in ART with egg donation, which is around $40-50 \%$ without a marked age-decline until the mid-40s, indicates that egg quality is the primary barrier to pregnancy in older women (CDC 2005). In addition to reduced fecundity, women aged 40 and over also face substantially higher risks of adverse outcome during pregnancy with respect to younger women (Dolk et al. 2005; Gourbin 2005; Jolly et al. 2000; Ziadeh and Yahaya 2001), and for women aged 45 and over, Dildy et al. (1996) found a higher incidence of pre-gestational and gestational complications.

While the decline of fecundability with a man's age is less documented, there is evidence of a significant decline by the late 30s (e.g., de la Rochebrochard and Thonneau 2005), potentially reinforced by a secular trend towards reduced sperm quality (Slama et al. 2004; Swan 2000). This finding is consistent with the high demand for ICSI treatment among couples seeking ART_about $30 \%$ of all in vitro cycles in Denmark and about 56\% in the U.S. are ICSI (Andersen and Erb 2006; 
CDC 2005)—reflecting the existence of a significant number of couples with predominantly male infertility, caused in most cases by testicular failure and poor semen quality. Jørgensen et al. (2006) have also estimated that as many as $30 \%$ of young Danish men may have semen quality in a subfertile range, and more than $10 \%$ may be in the infertile range-consistent with similar estimates for the U.S. (Acacio et al. 2000). Children of older men who are more likely to be affected by poor semen quality have an increased risk of schizophrenia and new mutation autosomal dominant disorders (Thacker 2004). There is also mounting evidence suggesting that changing lifestyles and environmental exposures to chemical substances, e.g., to endocrine disrupters, are behind the trends in occurrence of male reproductive health problems, including testis cancer, undescended testis and poor semen quality (Andersen and Erb 2006).

Our review of the literature on physiological factors affecting late fertility thus reveals a substantial controversy about the feasibility of widespread and reliable childbearing above age 35 for women, especially for first births. An example is the following summary statement (directed to women) by the American Society for Reproductive Medicine (2003): "Your fertility naturally declines as you get older. When this decline begins, however, and the rate at which it progresses vary widely in women. Generally, fertility begins to drop in your late 20 s or early 30 s and falls more rapidly after the age of 35." In vitro fertilization, intra uterine insemination and oocyte donation, may partially overcome some of the age-related declines in fecundity. In one of the few existing studies, for example, Leridon (2004) evaluates the probability for childless women to become mothers as a function of the age at the onset of the attempt to conceive. Leridon's simulation model shows that out of 100 women starting to become pregnant at age 30, 91 women will have a child without ART, 3 women will have a child thanks to ART and 6 women will remain childless. If the starting age is 40, 57 women will have a child without ART, 7 women will do so thanks to ART, and 36 women will remain childless. Hence, if the attempt to become pregnant begins at age 40 , ART will increase the probability of a successful pregnancy by merely 7 percentage points, or alternatively, ART reduces the number of women who remain involuntarily childless merely from 43 to 36 out of 100 who start an attempt to become pregnant at age 40. Leridon (2004) thus gives a two-fold recommendation: "The message for a woman aged <35 years trying to conceive is: be patient. [...] The message for women aged $>35$ years is: be impatient. The chances of a rapid spontaneous conception are still significant, but in case of failure, ART will not fully compensate for the years (and the chances of conceiving) lost." Consistent with these findings, Bewley et al.'s (2005) review similarly concludes that "[w]omen want to 'have it all,' but biology is unchanged; deferring defies nature and risks heartbreak. If women want room for manoeuvre [with respect to fertility] they are unwise to wait till their 30s."

Despite these skeptical and cautious perspectives in the medical literature, Beets et al. (1994) nevertheless argue that the information available to women may not be sufficient to make them aware of the uncertainties associated with plans for childbearing after age 35 . This potential lack of information about the feasibility of childbearing at advanced ages was even the theme of a 
Newsweek cover story 'The truth about fertility: Don't believe the hype-even fertility specialists say younger is better' (Newsweek, August 27, 2001). ${ }^{6}$ Moreover, in Bewley et al.'s (2005) eyes, the availability of in vitro fertilization (IVF) may "lull" women into infertility while they wait for a suitable partner and concentrate on their careers and achieving security and a comfortable living standard, while women may not recognize that this strategy is potentially expensive and prone to high failure rates. For instance, in IVF with non-donor eggs, by far the most common procedure, the failure rates per cycle to result in a live birth is more than $60 \%$ for women younger than age 35 , increasing to more than $85 \%$ for women in their early 40s (CDC 2005). Information campaigns in combination with technological progress in reproductive science, however, may improve women's ability to predict the change in fecundity with age. For instance, a recent study reports that a technique that uses a mathematical model and transvaginal sonography has been shown to be able to predict ovarian reserve, and thus the reproductive age which marks the distance of a woman from menopause. One of the concluding remarks of that study is that "The ability to make a direct assessment of ovarian reserve would be of enormous benefit to women who are being considered for assisted reproductive technologies, [...] and for women who are considering delaying starting a family for personal or professional reasons" (Wallace and Kelsey 2004).

\section{Towards the limit: trends in very late and latest-late fertility dur- ing the 20th century in Sweden}

\section{Data}

The data for our calculations stem from the Swedish population-register system, which covers with a high degree of accuracy the whole population of the country and its vital events. We make use of two main types of data. First, our analyses of long-term trends in late fertility and the latest ages of giving birth rely on accurate registration of births by age of the mother starting in the late 19th century. The main limitation of using this birth register is that, until 1954, the data are on deliveries rather than on births. For what concerns long-term trends, however, this limitation is not severe, as we cannot notice a clear break in the time series around 1954. Second, for our analyses of first birth fertility above age 40, we utilize occurrence-exposure rates based on the number of first births and on the number of childless women that are available for the cohorts born from 1925 onwards and for the periods since 1970. The occurrence-exposure rates are derived from the longitudinal information on the dates of each recorded birth of all women in Sweden (see also Andersson 1999; Andersson and Guiping 2001). 


\section{Trends in very late and latest-late childbearing}

Figure 1(a) graphs the number of births from mothers aged 40 and over during the period from 1900 to 2001. The two lines represent the absolute number (scale on the left vertical axis) and the fraction of births to mothers aged 40+ years among all births (per thousand, scale on the right vertical axis). The figure clearly reveals a reduction of births at advanced ages (40 years and above) from the beginning of the 20th century until the end of the 1970s, both in absolute and in relative terms. This trend mirrors the pattern already discussed in Table 1 for Sweden and other developed countries. At the end of the 1970s, the decrease in the absolute number and fraction of births to mothers aged 40 and over stops and ultimately reverses, followed by a relatively slow upward trend until the end of the century. In particular, the highest number of births to mothers aged 40 and over occurs at the beginning of the time series in 1900, and is equal to 16,125 births, or 115.5 births per thousand total births occurring during the year 1900. The minimum is reached in 1977, with 823 births or 8.6 per thousand total births occurring in the calendar year 1977. In 2001, the figure is up to 2,450 births or 26.8 per thousand total births.

A similar pattern can be observed for latest-late births, i.e., those to mothers aged 45 and over (Figure 1b). The long-term downward trend starts from a maximum of 1,716 births (12.2 per thousand total births) in 1901, reaches the minimum number of 31 births ( 0.3 per thousand total births) in 1980, and turns to a slow upward trend, reaching 89 births (1.0 per thousand total births) in 2001. The share of births to women aged 45 and above among all births to women aged 40 and over has also declined during 1900-80, with a stabilization-or even a timid reversal-in more recent years (Figure 2). In particular, at the beginning of the twentieth century, births to mothers aged 45 and over were around one tenth of all births to mothers aged 40 and over, this figure has declined to about 3-4 per cent at the end of the observation period.

While childbearing at ages $40+$ and $45+$ currently remains well below the levels observed earlier in the 20th century and prior to the demographic transition, extreme cases of mother's age at birth have occurred in recent years. Figure 3 shows the highest annual ages at birth during the 20th century in Sweden. While the analyses of extreme ages has received considerable attention in the research on mortality (e.g., Wilmoth et al. 2000; Wilmoth and Lundström 1996), this has surprisingly not been the case in fertility, perhaps for reasons of data quality. The dots in this figure represent the highest age at birth in any given calendar year, and the line depicts a 5-year moving average that better represents trends. Figure 3 reveals that the extreme age at birth in Sweden has been stable around the age of 51 from the end of the nineteenth century to the pre-WWII period. (Until 1954 we have to take into account that the extreme age at birth may sometimes be overestimated, as our data refer to deliveries, including still births, rather than to live births.) Subsequently this extreme age declined, reaching a trough in the late 1970s. This decline also corresponds with the decline in the absolute and relative number of births to women aged 40+ or $45+$ years old. From the 1980s, this trend reverses and the oscillation around age 51-which has been characteristic for the first part of the 20th century-is again restored. In addition, there 
(a) Absolute and relative number of births at age 40 and over

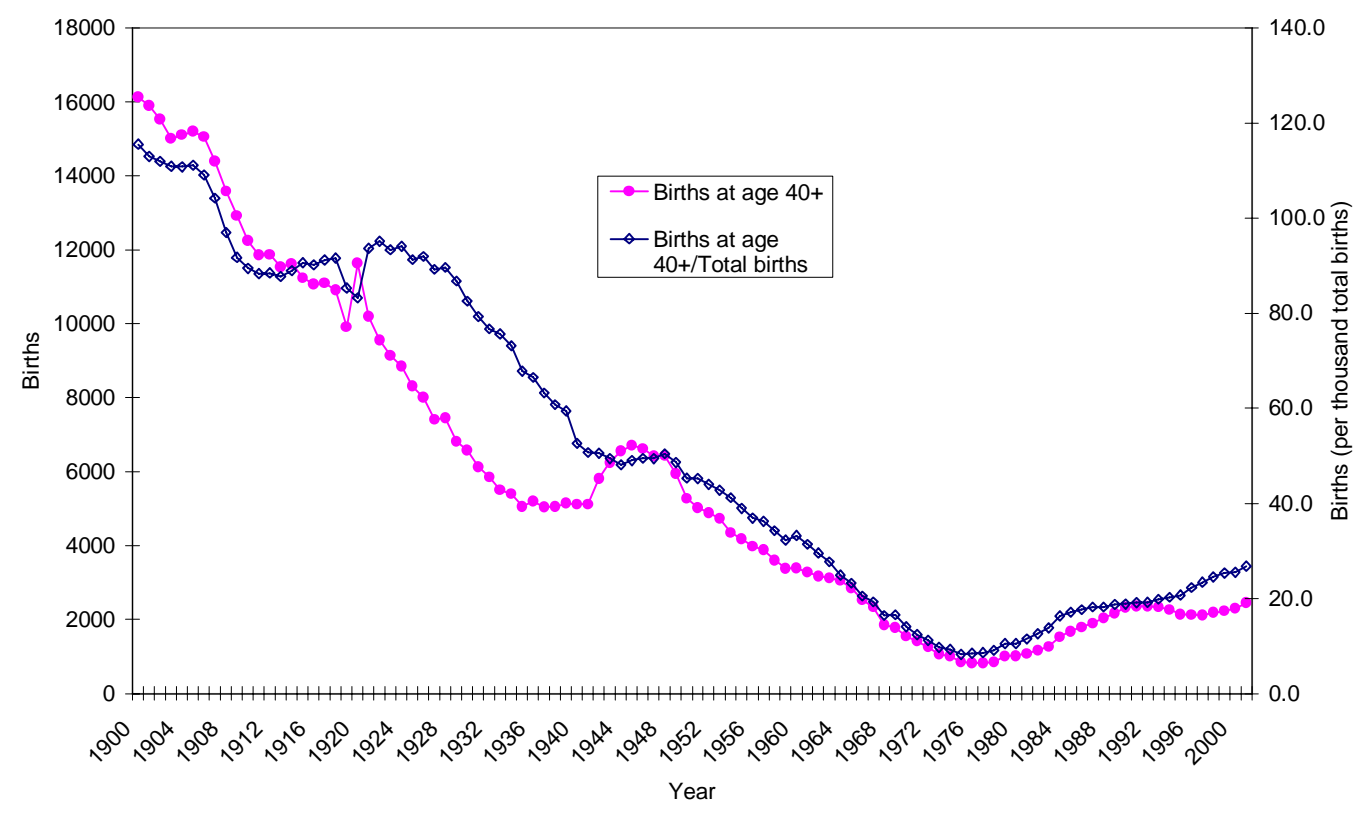

(b) Absolute and relative number of births at age 45 and over

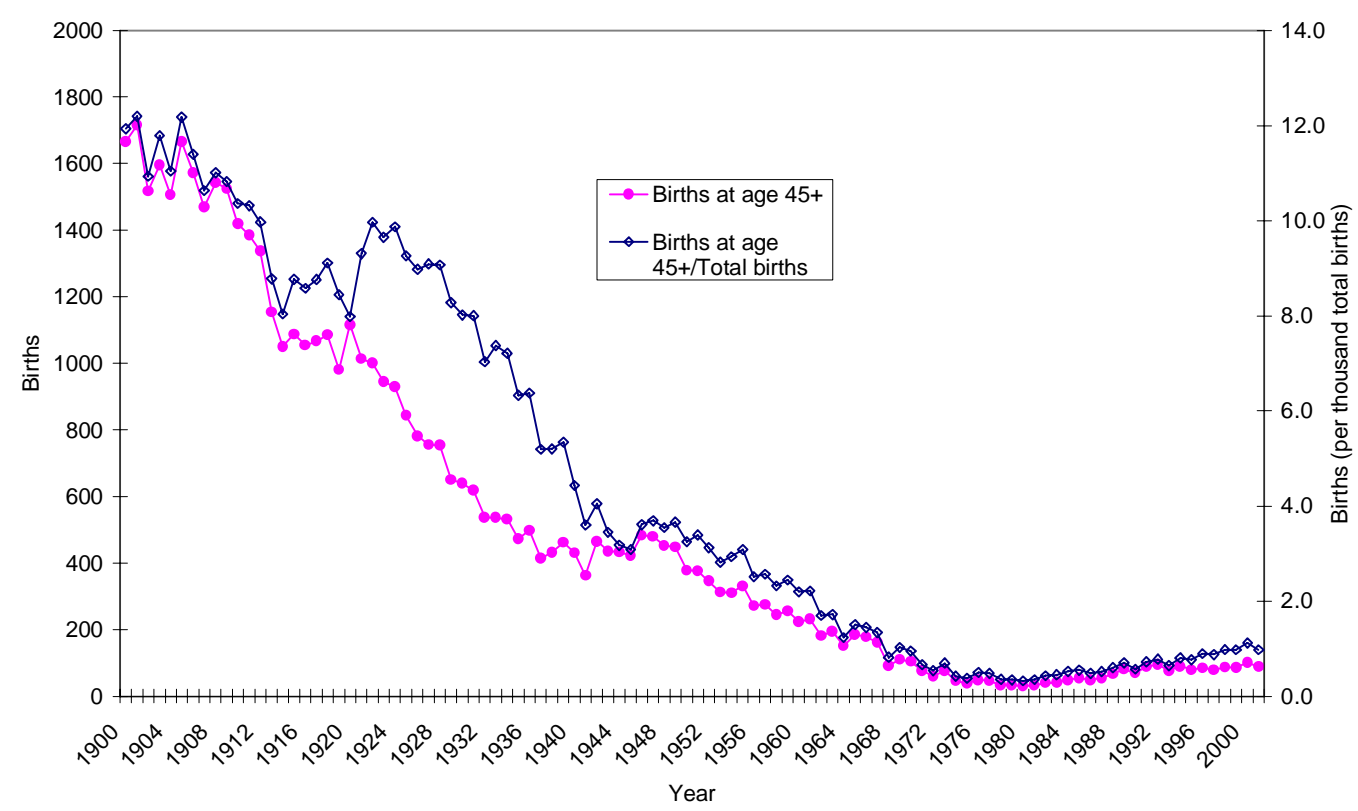

Figure 1: Very late and latest-late births in Sweden, 1900-2001 (Note: data until 1954 pertain to deliveries, and from 1955 onwards to live births) 


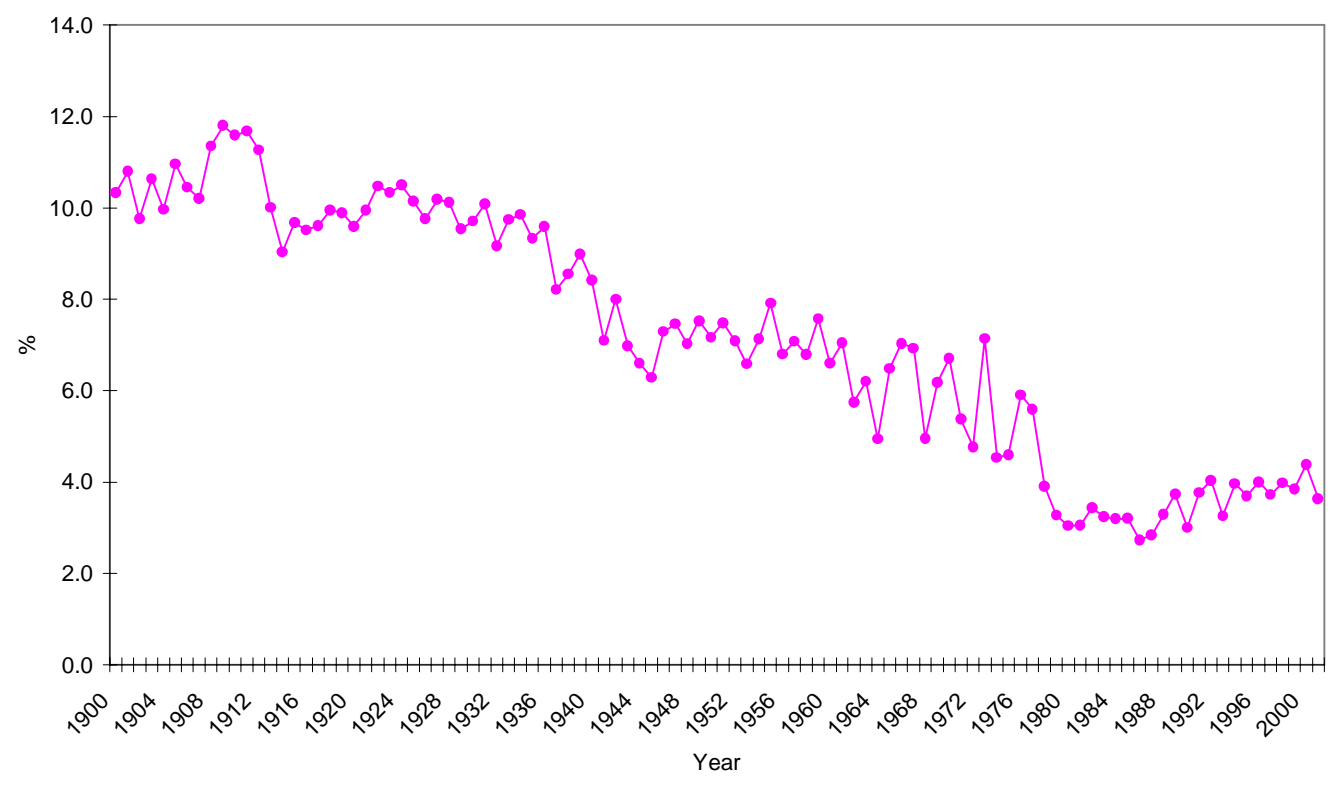

Figure 2: Percentage of births to women aged 45 and over among all births to women aged 40 and over, 1900-2001

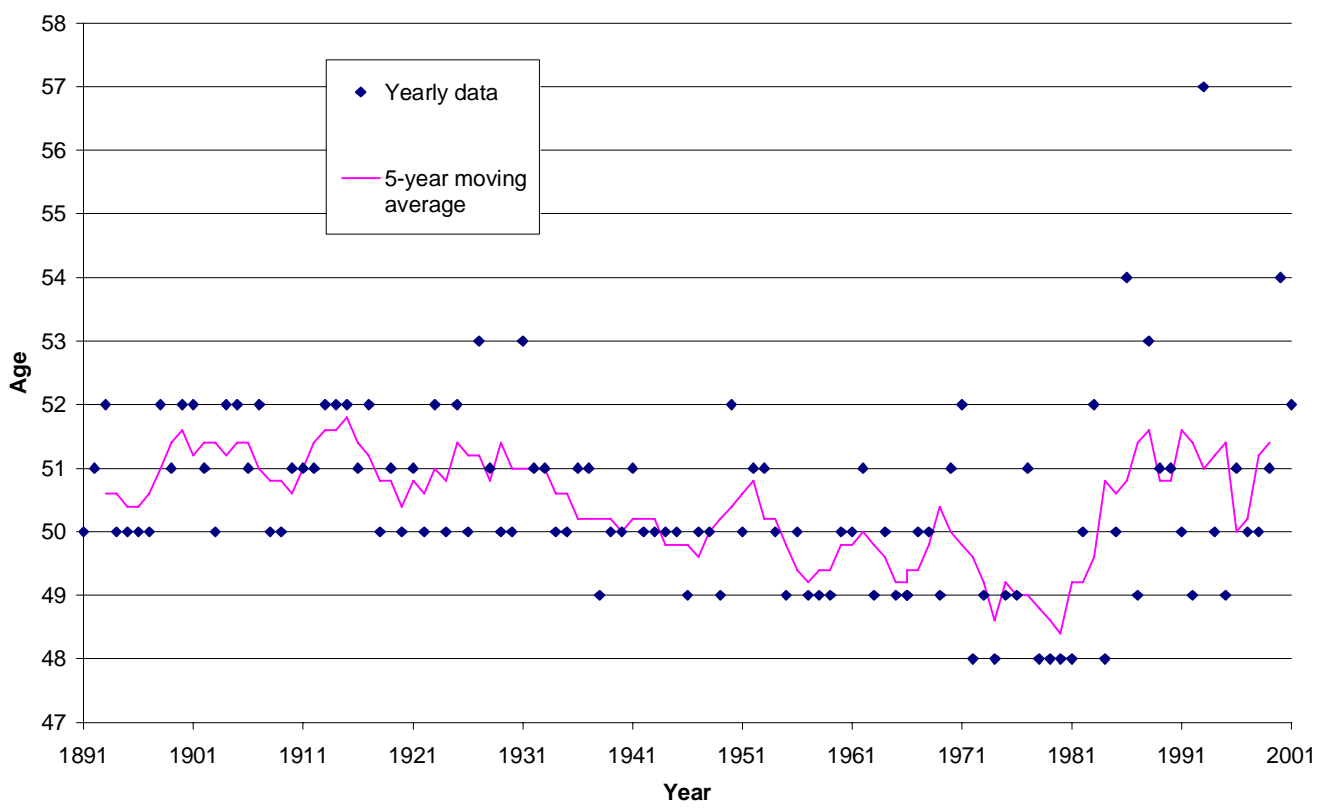

Figure 3: Extreme age at birth in Sweden, 1891-2001 
is some indication that the extreme age at birth is increasing during the 1990s. For instance, the oldest Swedish woman giving birth during the 20th century has been recorded in 1993 at the age of 57, and the oldest women giving birth was 53 years or older in four years during 1986 to 2000_in contrast, an age at birth of 53 years or higher was only attained twice in the remaining 90 years of our time series prior to 1986. Moreover, this trend towards new records in extreme ages at giving birth towards the end of the 20th century occurs in a context of a historically relatively small number of births to women aged $40+$ or $45+$ years. If "chance occurrences" of extreme ages at birth were the primary mechanism underlying the patterns in Figure 3, we would expect that extremes were concentrated in periods with the highest number of births above age 40, that is, early in the 20th century rather than at the end.

In summary, the above analyses reveal that, until the late 1970s, the trends in childbearing at advanced ages during the 20th century were characterized by a decline in the absolute and relative number of births to women aged $40+$ or $45+$ years. In addition, the share of births to women aged $45+$ years among births to women aged 40+ years also declined during this period. The beginning of the 1980s marks a clear break. The number of births to women aged 40+ years started to increase both in absolute and relative terms from its trough at the end of the 1970s, reaching again $2.7 \%$ of all births in 2001, three times the contribution of fertility at age 40 and over to overall fertility in 1977 . The absolute and relative number of births to women aged 45+ years also increased after a trough in 1980. While the increase is of similar relative magnitude, childbearing at ages 45 and over constitutes only a tiny fraction ( 1 per thousand) of overall births in 2001; moreover, despite the hype about that fertility postponement is pushing the limit of late childbearing, the fraction of births above age 45 among all births to women aged 40 years or over has declined substantially from its peak early in the 20th century, and it has not increased markedly since the 1980s. This constant contribution of births after age 45 to very late fertility (age 40 and above) reflects the fact that the last two decades of the 20th century witnessed an increase in childbearing at advanced ages (births to women aged 40+ years) and at very advanced ages (births to women aged $45+$ years) of approximately equal magnitude. At the same time, the absolute number of births to women aged $40+$ or $45+$ years, as well as the contribution of these births to overall fertility, is currently well below the levels observed earlier in the 20th century until about 1960. The absolute and relative contribution of childbearing at advanced and very advanced ages therefore remains relatively low in contemporary Sweden if compared to historical levels, despite the fact that Sweden has experienced a marked postponement of fertility since the 1970s that has resulted in a mean age at first birth of 28.2 years in 2001. In addition, the analyses of extreme age at birth during the 20th century indicates a breakpoint around 1980 at which the earlier tendency towards younger extreme ages at birth is reversed. In the 1980s and 1990s the earlier pattern of 51 years being the oldest age at which women give birth in any given calendar year is restored, and there are even signs that the age limit of fertility is pushing a new extreme during the 1990s. Undoubtedly, this trend is connected with the recent progress in reproductive technologies that has 
accelerated and proliferated since the 1980s (Socialstyrelsen 1998).

It is important to note that the long-term trends in childbearing above age 40 probably mask an important change in the birth order of children born to women aged 40 and older. Our data do not allow us to investigate these long-term trends further at this point. However, it is likely that early in the 20th century the contributions to late childbearing were primarily by very fecund women (or couples) who had a relatively large number of children, and first or second children at ages 40 and above were presumably relatively rare. At the end of the 20th century, the contribution of first and second children to fertility above age 40 has substantially increased. This is likely to have occurred for two reasons. First, children of high birth order have become rare, and childbearing across all ages is increasingly dominated by first and second children. Second, the delay of entering parenthood has increased the fraction of women who are childless or at parity one as they reach age 40, and this increased fraction of low-parity women at advanced or very advanced childbearing ages is likely to raise the fraction of $40+$ fertility that is due to first and second children.

\section{Trends in first-birth rates}

For the period from 1971 onward, our analyses of late fertility in Sweden can additionally utilize occurrence-exposure fertility rates for first children, that is, rates that relate first births to the number of childless women, second births to the number of women at parity one, etc. These rates have the advantage that they are not affected by changes in the number of women at different parities at advanced ages, which is important since the population parity distribution varies with differential fertility behavior of cohorts.

The top panel of Figure 4 reports the trends in first-birth occurrence-exposure rates for women aged 40-44 during the period 1971-2002, and the bottom panel reports the corresponding rates for ages 45-48. Similar to our earlier analyses, Figure 4 reveals a plateau during the 1970s, followed by a clear upward trend in fertility rates for first births. Since our analyses are based on occurrence-exposure rates, this trend reflects an increased propensity of childless women at advanced childbearing ages to have children and become mothers. There are, however, important differences across ages. At ages 40-41 years, first-birth rates have more than doubled during 19712000. Fertility rates at ages 43-44 have doubled too. Above age 45, however, there has only been a very modest increase or no increase at all. Despite the substantial delay of childbearing during this period, childless women above age 45 therefore did not experience a marked increase in their propensity to have children, in striking contrast to increases in the propensity to have first children for women who are in their early 40s. This trend also persists at the cohort level (not shown here in detail): While there have been marked increases in fertility rates for childless women around age 40 , after age 44 there has been a remarkable stability in the propensity to become a first-time mother across about 30 birth cohorts born during 1925-1957.

In summary, therefore, increases during the time period 1971-2002 in the propensity to become 
(a) First birth rates (occurrence/exposure rates, per 1000 woman-months as childless) at ages 40-44

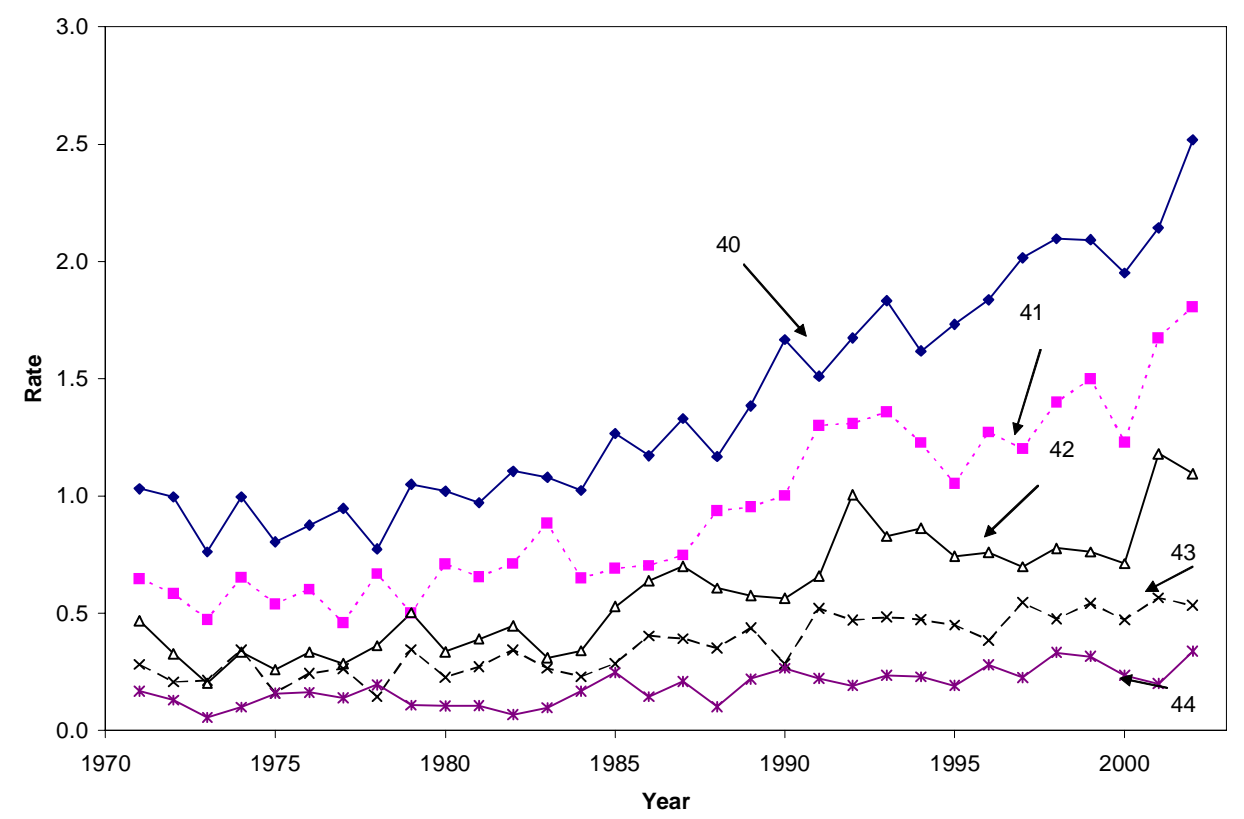

(b) First birth rates (occurrence/exposure rates, per 1000 woman-months as childless) at ages $45-48$

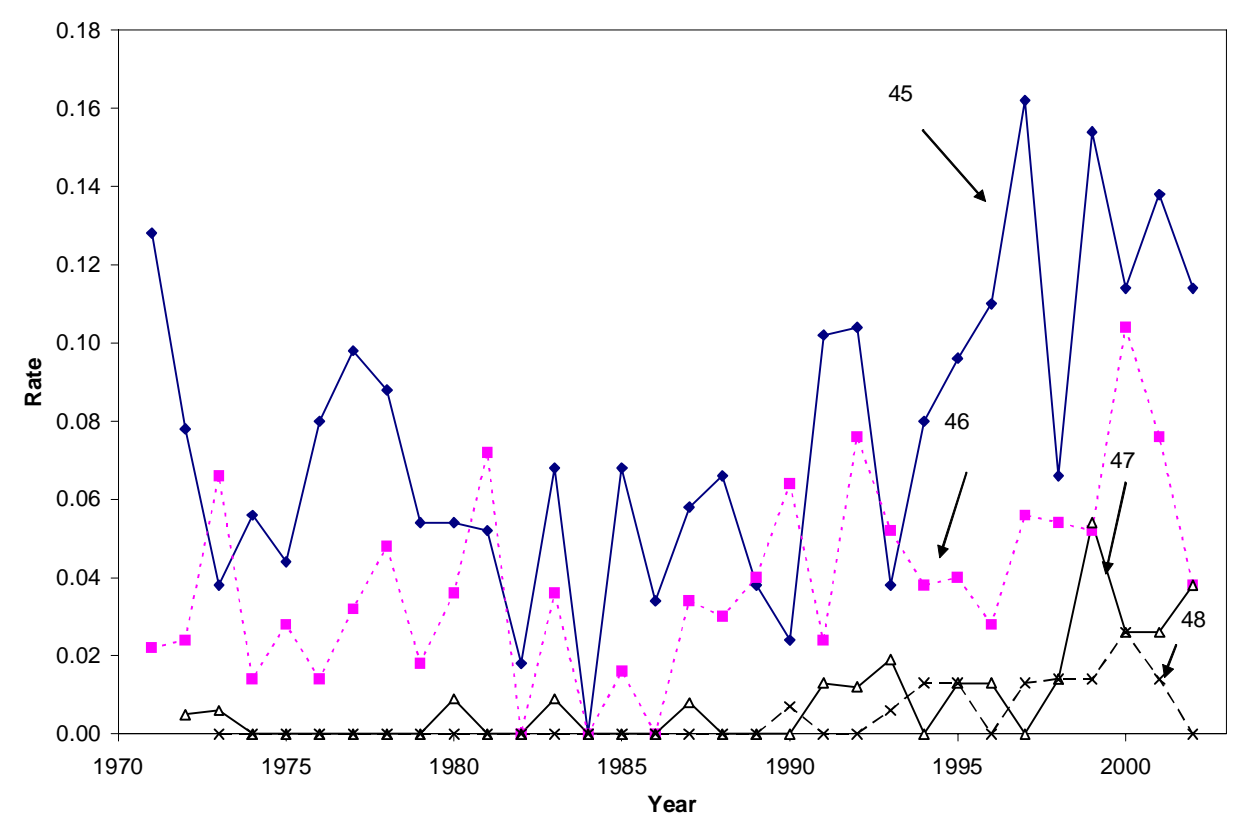

Figure 4: Very late and latest-late first-birth fertility rates (per 1000 woman-months as childless) in Sweden, 1971-2002 
a first-time mother are concentrated at ages in the early forties, where the changes have been substantial and first-birth rates have more than doubled. Above age 44 or 45 , this trend towards increased fertility rates has been absent or at best very modest. Despite the increases of fertility rates for ages in the early forties, however, the probability for a childless woman to experience a first-birth at advanced ages remains small and far below the figures estimated by Leridon. In 2002 , for instance, the probability of a 40-year old childless woman to ever have a child is 7.48 per cent, compared to 3.26 percent in 1970. For a 45 year old childless woman the probability to have a child is 0.23 percent based on the 2002, as compared to 0.17 percent based on the 1970 fertility rates. This lack of absolute change in first-birth probabilities at very advanced ages, despite the substantial overall postponement of fertility, may be due to the fact that $(a)$ women who are childless at ages above 45 have either chosen to remain permanently childless, and/or $(b)$ the probabilities to have children at these very advanced ages remain very small, despite the recent progress in reproductive technologies, due to the low probabilities of conceptions and successful pregnancies at these ages. While our data cannot disentangle these two factors, it is nevertheless apparent from our analyses that the postponement of fertility in the last three decades has not (yet) resulted in an increase in the fertility rates of childless women at very advanced reproductive ages.

\section{Rectangularization of the transition to motherhood?}

Women in their twenties and early thirties can continue to postpone childbearing to later ages, while the opportunities for further postponement are quite limited for women at more advanced ages of childbearing due to the upper age limits in childbearing. Consistent with these age limits, the increases in fertility rates above age 40 - and particularly above age 45- have been fairly modest. Borrowing a popular idea on human longevity (Wilmoth and Horiuchi 1999), one may therefore foresee a rectangularization of the transition to motherhood, or, equivalently, compression of the transition to motherhood within a short age span. This rectangularization would be characterized by a concentration of childbearing in an increasingly narrow age interval. As a result, few women would have children prior to, say, age 28 or 29 , and childbearing at parity one and two will be concentrated when women are in their thirties. There will be very few higher parity births, especially among women with a late onset of childbearing. ${ }^{7}$

A good measure of the rectangularization of the transition to motherhood is the interquartile range in the age at first birth. The interquartile range has been suggested as the most important measure of rectangularization for mortality by Wilmoth and Horiuchi (1999). Its application to fertility only requires the additional consideration of the fertility quantum, that is, the fact that not every woman experiences a birth. We therefore propose to calculate the interquartile range in the age at first birth in two ways: First, by focusing on all women who had at least one birth (similarly to measures such as the mean age at first birth or the standard deviation of age at first birth). For simplicity let us call this interquartile range type I. Second, by focusing on all women, 
including those who did not have births and resulting in a measure we call interquartile range type II. The interquartile range type I is the difference between the ages when $25 \%$ and $75 \%$ of women, who ultimately experience a first birth, have become mothers. ${ }^{8}$ Contrary to the above hypothesis that substantial fertility postponement is likely to be associated with a rectangularization, Sobotka (2004) shows that the interquartile range type I has increased in many European countries, including also CEE countries, during the period 1985-2000.

For Sweden, the dynamics of the interquartile range for first births (Figure 5) is quite different for type I and type II and for period versus cohort data. If period data is considered (Figure 5a), the type I interquartile range has been fairly stable in the period 1961-2002 at a value of about 6 years with a slight increase to about 6.5 years in the most recent periods. The interquartile range type II has fluctuated substantially across periods, which is related to the marked changes in period fertility levels that is associated with strongly varying levels of childlessness in synthetic calendar-year cohorts. ${ }^{9}$ Independent of the choice of type I or type II interquartile ranges, the period analyses in Figure 5(a) do not provide a clear evidence for a rectangularization of fertility. The pattern changes if the analyses are conducted on the cohort level (Figure $5 b)^{10}$. Initially, the interquartile range type I for first births decreased from cohort 1925 and reached a minimum of 5.7 years for cohorts 1940-1941. From cohort 1941, there has been a steady increase in the interquartile range, reaching a maximum of 7.5 years for cohort 1956 . From the 1956 cohort onwards, there has been a fast reversal of this trend, and the interquartile range declined to 6.8 years for the cohort born in 1961, representing a decline of $10.5 \%$ from the 1956 cohort. This trend is almost identical in analyses based on the type II interquartile range, and is consistent with a trend towards the rectangularization of the transition to motherhood in the most recent cohorts.

\section{Summary and discussion}

To sum up, whither late fertility? In this paper we have analyzed fertility by focusing on what we defined very late fertility (i.e., fertility at age 40 or above) and latest-late fertility (i.e., fertility at age 45 or above). Although the literature focusing on physiological factors related to late fertility is, broadly speaking, skeptical on fertility outcomes already around a female age around 35, most evidence on the fact that limits are being approached is on ages 40 and above. Our empirical longterm analysis of Swedish data has shown that the beginning of the 1980s marks a break with the trend concerning late fertility, with an increase in the number of births to women aged 40+ years and $45+$ years. Nevertheless, fertility at ages $45+$ still constitutes only a tiny fraction of overall births in 2001, and the contribution of very late and latest-late fertility is currently well below the levels observed earlier in the 20th century until about 1960. For what concerns first births, recent increases in the propensity to become a first-time mother around age 40+ have been substantial, while at ages $45+$ this trend towards increased fertility rates has been modest.

Is the upper age limit of fertility changing? We followed the tradition of the analysis of oldest- 
(a) Period data (years 1961-2002)

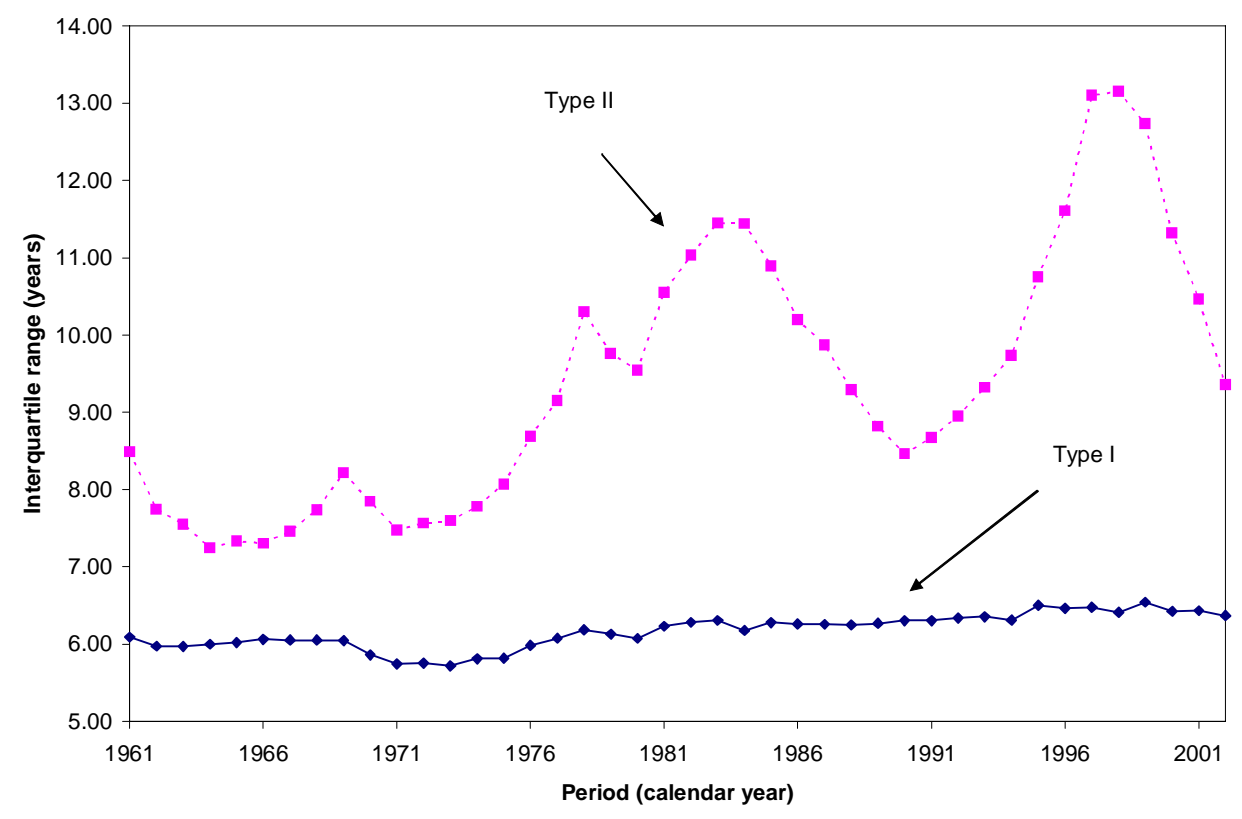

(b) Cohort data (cohorts 1925, 1930, 1935, 1940, 1941,1942,...)

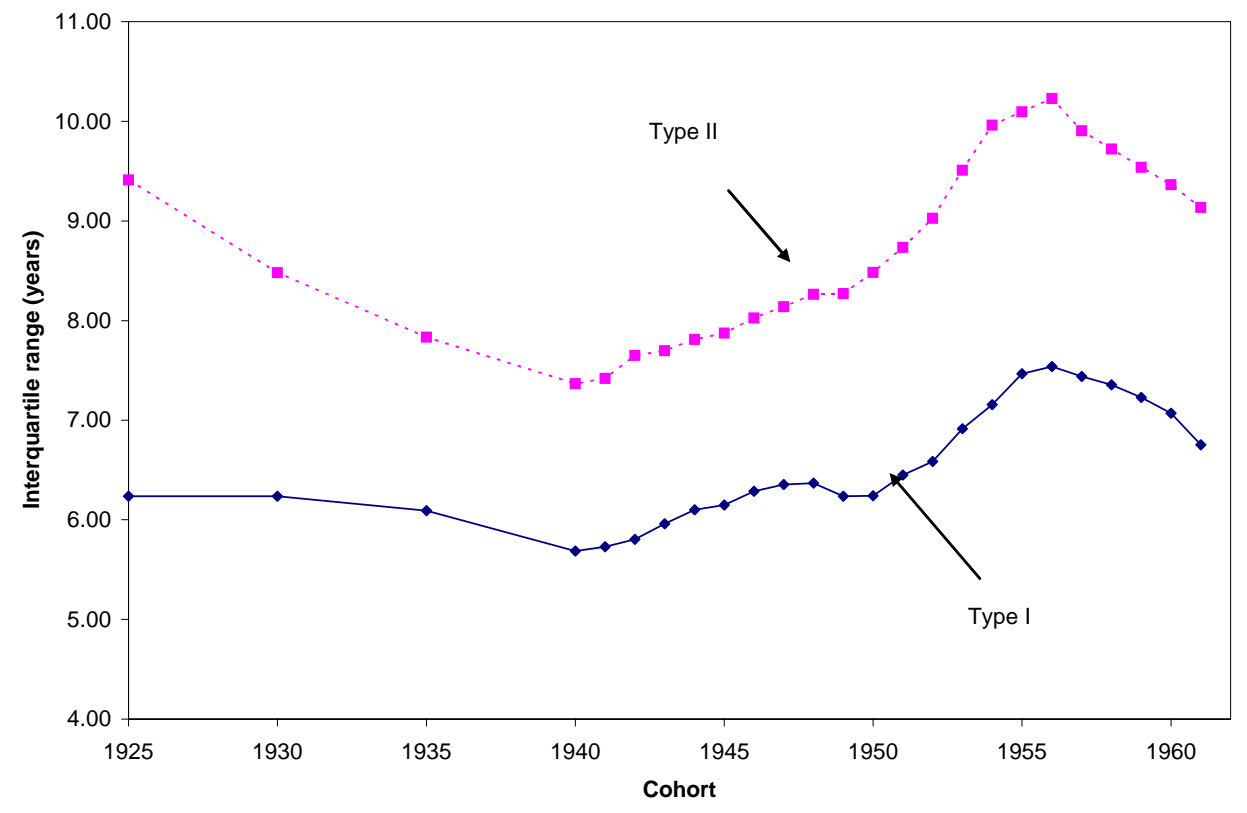

Figure 5: Interquartile range at first birth (type I and type II) for Sweden based on period and cohort data. 
old mortality to study the extreme cases of latest-late fertility, by focusing on cross-sectional extreme ages at birth. Our analyses indicate, again around 1980, a reversal in the tendency towards younger extreme ages at birth that was linked with the historical decrease in family size. There are clear signs that the upper age limit of fertility has been pushed to a new extreme during the 1990s, as a likely result of the progress in reproductive technologies. We could speculate that upper limits will extend further if technologies allow for a more widespread practice of egg donation, or more likely, of the strategy to freeze one's own eggs at younger ages to make use of them at later ages. Whether such development might have an impact on overall fertility rates is not clear at this moment.

Do we observe signs of a rectangularization of fertility? Our analyses did not reveal clear trends towards a rectangularization of fertility, i.e., a situation in which a common choice to postpone first births reduces the variability of ages at first birth. In our view two reasons might explain this lack of rectangularization. A first reason might be the prevalence of a two- to three-child norm in Sweden and other countries (Goldstein et al. 2003), which introduces a higher variability in age at first birth with respect to the extreme situation in which a woman has at most one child. Rectangularization might be a situation to which we tend to, but only in societies with a trend toward a one-child norm - this might be the case because one child satisfies nurturing needs (Foster 2000) and additional children do not appear to influence positively a woman's happiness (Kohler et al. 2005). A second reason for the lack of rectangularization might be an increasing 'individualization' of life course experiences as expected from the Second Demographic Transition idea (Lesthaeghe and van de Kaa 1986; van de Kaa 1987)_-this might be supported by the evidence of a general increase in the heterogeneity of the timing of first birth (Sobotka 2004). The latter argument is supported by findings of newly emerged differences in the timing of childbearing across regions in Sweden (Kulu et al. 2006). Nevertheless, it may still be premature to expect a rectangularization of fertility since the peak of age-specific fertility rates is just beginning to increase above age 30 in Sweden and some other developed countries.

Do we know enough? We believe we now know more, but population-level research on very late and latest-late fertility looks like being at an early stage of progress. Main statistical agencies, as we have documented, are only starting to notice the changes needed for their age categories. Standard demographic surveys seldom provide a large enough sample to study very late and latestlate fertility. Prospective studies on the long-term consequences for children are not yet in place. For sure, these topics will become central in future research. 


\section{Notes}

${ }^{1}$ Accessed on October 4, 2006

${ }^{2}$ Accessed on October 4, 2006

${ }^{3}$ For instance, see Kohler and Ortega (2004) for a general discussion of tempo and compositional influences on period fertility measures.

${ }^{4}$ Own calculations based on Martin et al. (2005) and Eurostat (http://epp.eurostat.cec.eu.int, accessed Feb 20, 2006).

${ }^{5}$ We follow the CDC definition for assisted reproductive technologies (ART) that includes all fertility treatments in which both eggs and sperm are handled (CDC 2005). In general, ART procedures involve surgically removing eggs from a woman's ovaries, combining them with sperm in the laboratory, and returning them to the woman's body or donating them to another woman. They do not include treatments in which only sperm are handled (i.e., intrauterine — or artificial—insemination) or procedures in which a woman takes drugs only to stimulate egg production without the intention of having eggs retrieved.

${ }^{6}$ The cover story also refers to a new generation of celebrities who seem to be new 'trend-setters' by having their first babies in their 20s. The examples mentioned in the article include Belgium's Princess Mathilde, Jade Jagger, French model Laetitia Casta and actress Kate Winslet.

${ }^{7} \mathrm{~A}$ first discussion of such a potential rectangularization of the transition to motherhood in Spain, the Netherlands and Sweden is found by Kohler and Ortega (2002), where the most recent increases in the mean age of the childbearing intensity schedules for first births have been associated with a decreasing standard deviation of the schedule. In Spain, for instance, the standard deviation declined from 5.4 to 4.7 (-11\%) during 1980-98, while the mean increased from 26.7 to $30.8(+16 \%)$.

${ }^{8}$ The calculations first compute the probability $P(x)$ of having a first birth prior to age $x$ for women in a synthetic cohort who experiences the period childbearing intensities in a calendar year. We then condition on giving birth to at least one child and compute $P^{*}(x)=P(x) / P(\omega)$, where $\omega$ is the oldest age at childbearing (i.e., age 50). We then use linear interpolation to calculate the ages where $P^{*}(x)$ equals .25 and .75 . The interquartile range is the difference between these ages.

${ }^{9}$ The correlation coefficient between type II interquartile range and the level of childlessness at age 40 is .97; for a discussion of changes in childlessness for synthetic cohorts, see also Kohler and Ortega (2002).

${ }^{10} \mathrm{We}$ compute the interquartile range type I using women who had their first child before age 40 to be able to use cohorts born until 1961 for our calculations. 


\section{References}

Acacio, B. D., T. Gottfried, R. Israel and R. Z. Sokol. 2000. "Evaluation of a large cohort of men presenting for screening semen analysis," Fertility and Sterility 73(3): 595-597.

American Society for Reproductive Medicine. 2003. Age and Fertility: A Guide for Patients. Birmingham, AL: American Society for Reproductive Medicine. Available online at http://www.asrm.org/Literature/patient.html.

Andersen, A.-M. N., J. Wohlfahrt, P. Christens, J. Olsen and M. Melbye. 2000. "Maternal age and fetal loss: A population based linkage study,” British Medical Journal 320: 1708-1712.

Andersen, A. N. and K. Erb. 2006. "Register data on assisted reproductive technology (ART) in Europe: Including a detailed description of ART in Denmark," International Journal of Andrology 29(1): 12-16.

Andersson, G. 1999. “Childbearing trends in Sweden 1961-1995,” European Journal of Population 15(1): 1-24.

Andersson, G. and L. Guiping. 2001. "Demographic trends in Sweden: Childbearing developments in 1961-1999, marriage and divorce developments in 1971-99," Demographic Research 5(3): 65-78. Available online at http://www.demographic-research.org.

Auger, J. and P. Jouannet. 2005. "Age and male fertility: Biological factors," Revue d'Épidémiologie et de Santé Publique-Epidemiology and Public Health 53(Hors-Série 2): 2535.

Beets, G., E. te Velde, P. Verloove-Vanhorick, H. Merkus and H. Bruinse. 1994. "Medical complications of aging fertility," in G. Beets, H. van den Brekel, R. Cliquet, G. Dooghe and J. de Jong Gierveld (eds.), Population and Family in the Low Countries 1993: Late Fertility and Other Current Issues. Amsterdam: Swets and Zeitlinger, pp. 1-23.

Bewley, S., M. Davies and P. Braude. 2005. "Which career first? The most secure age for childbearing remains 20-35," British Medical Journal 331: 588-589.

Billari, F. C. and G. A. Micheli. 1999. "Le scelte demografiche. La percezione dei costi e delle norme sociali," in L. Mauri and F. C. Billari (eds.), Generazioni di donne a confronto. Indagine sociodemografica. Milano: Franco Angeli, pp. 163-190.

Billari, F. C. and A. Rosina. 2001. "The effect of age on time until ovulation in female menstrual cycles. A longitudinal data analysis based on mixed models," Genus 57(2): 71-87.

Birrittieri, C. 2004. What Every Woman Should Know About Fertility and Her Biological Clock. Franklin Lakes, NJ: The Career Press.

Bongaarts, J. 1983. "The proximate determinants of natural marital fertility," in R. A. Bulatao and R. D. Lee (eds.), Determinants of Fertility in Developing Countries. New York: Academic Press, pp. 103-138.

- 2002. "The end of the fertility transition in the developed world," Population and Development Review 28(3): 419-444. 
Bongaarts, J. and G. Feeney. 1998. "On the quantum and tempo of fertility," Population and Development Review 24(2): 271-291.

Brewis, A. and M. Meyer. 2005. "Marital coitus across the life course," Journal of Biosocial Science 37: 499-518.

CDC. 2005. Reproductive Technology Success Rates. Atlanta, Georgia: Center for Disease Control and Prevention. Available online at www.cdc.gov/art/art2003.

Colombo, B. and G. Masarotto. 2000. "Daily fecundability: First results from a new data base," Demographic Research 3(5). Available online at http://www.demographic-research.org.

Council of Europe. 2004. Recent Demographic Developments in Europe. Strasbourg: Council of Europe Publishing. Available also online at http://www.coe.int.

de Bruin, J. P., H. Bovenhuis, P. A. H. van Noord, P. L. Pearson, J. A. M. van Arendonk, E. R. te Velde, W. W. Kuurman and M. Dorland. 2001. "The role of genetic factors in age at natural menopause," Human Reproduction 16(9): 2014-2018.

de la Rochebrochard, E. and P. Thonneau. 2005. "Paternal age: Are the risks of infecundity and miscarriage higher when the man is aged 40 and older," Revue d'Épidémiologie et de Santé Publique-Epidemiology and Public Health 53(Hors-Série 2): 47-55.

Dildy, G. A., G. M. Jackson, G. K. Fowers, B. T. Oshiro, M. W. Varner and S. Clark. 1996. "Very advanced maternal age: pregnancy after age 45," American Journal of Obstetrics and Gynecology 176(3): 668-674.

Dolk, H., M. Loane, E. Garne, H. de Walle, A. Quesser-Luft, C. de Vigan, M. C. Addor, B. Gener, M. Haeusler, H. Jordan, D. Tucker, C. Stoll, M. Feijoo, D. Lillis and F. Bianchi. 2005. "Trends and geographic inequalities in the prevalence of Down syndrome in Europe, 1980-1999," Revue d'Épidémiologie et de Santé Publique-Epidemiology and Public Health 53(Hors-Série 2): 8795.

Dunson, D. B., B. Colombo and D. D. Baird. 2002. "Changes with age in the level and duration of fertility in the menstrual cycle," Human Reproduction 17(5): 1399-1403.

Foster, C. 2000. "The limits to low fertility: A biosocial approach," Population and Development Review 26(2): 209-234.

Fretts, R. C., J. Schmittdiel, F. H. McLean, R. H. Usher and M. B. Goldman. 1995. “Increased maternal age and the risk of fetal death," The New England Journal of Medicine 333(15): 953957.

Goldstein, J. R., W. Lutz and M. R. Testa. 2003. "The emergence of sub-replacement family size ideals in Europe," Population Research and Policy Review 22(5-6): 479-496.

Gougeon, A. 2005. "The biological aspects of risks of infertility due to age: The female side," Revue d'Épidémiologie et de Santé Publique-Epidemiology and Public Health 53(Hors-Série 2): 37-45.

Gourbin, C. 2005. "Foetal mortality, infant mortality, and age of parents," Revue d'Épidémiologie et de Santé Publique-Epidemiology and Public Health 53(Hors-Série 2): 81-86. 
Grant, J., S. Hoorens, F. Gallo and J. Cave. 2006. Should ART Be Part of a Population Policy Mix? A Preliminary Assessment of the Demographic and Economic Impact of Assisted Reproductive Technologies. Santa Monica: RAND Corporation. Available online at http://www.rand.org.

Henry, L. 1953. Fécondité des mariages: nouvelle méthode de mesure. Paris: INED, Cahier No 16. English Translation: Fertility of Marriage: A New Method of Measurement, UN/ESCAP Population Studies Translation Series No. 3, 1980.

—. 1961. "Some data on natural fertility," Eugenics Quarterly 8(2): 81-91.

Hewlett, S. A. 2002. Creating a Life: Professional Women and the Quest for Children. New York: Talk Miramax Books.

Jolly, M., N. Sebire, J. Harris, S. Robinson and L. Regan. 2000. "The risks associated with pregnancy in women aged 35 years or older,' Human Reproduction 15(11): 2433-2437.

Jørgensen, N., C. Asklund, E. Carlsen and N. E. Skakkbæk. 2006. "Coordinated European investigations of semen quality: results from studies of Scandinavian young men is a matter of concern," International Journal of Andrology 29(1): 54-61.

Kaufert, P. A., P. Gilbert and R. Tate. 1987. "Defining menopausal status: The impact of longitudinal data," Maturitas 9: 217-226.

Kohler, H.-P., J. R. Behrman and A. Skytthe. 2005. "Partner + children = happiness? An assessment of the effect of fertility and partnerships on subjective well-being in Danish twins," Population and Development Review 31(3): 407-445.

Kohler, H.-P., F. C. Billari and J. A. Ortega. 2002. "The emergence of lowest-low fertility in Europe during the 1990s," Population and Development Review 28(4): 641-681.

_. 2006. "Low fertility in Europe: Causes, implications and policy options," in F. R. Harris (ed.), The Baby Bust: Who will do the Work? Who Will Pay the Taxes? Lanham, MD: Rowman \& Littlefield Publishers, pp. 48-109.

Kohler, H.-P. and J. A. Ortega. 2002. "Tempo-adjusted period parity progression measures: Assessing the implications of delayed childbearing for fertility in Sweden, the Netherlands and Spain," Demographic Research 6(7): 145-190. Available online at http://www.demographicresearch.org.

- 2004. "Old insights and new approaches: Fertility analysis and tempo adjustment in the age-parity model," Vienna Yearbook of Population Research 2004 2: 57-89. (online available at http://www.oeaw.ac.at/vid/).

Kulu, H., A. Vikat and G. Andersson. 2006. "Settlement size and fertility in the Nordic countries”. MPIDR Working Paper, WP 2006-024. Max Planck Institute for Demographic Research, Rostock.

Larsen, U. and J. W. Vaupel. 1993. "Hutterite fecundability by age and parity: Strategies for frailty modeling of event histories," Demography 30(1): 81-102.

Lee, R. D. and J. R. Goldstein. 2003. "Rescaling the life cycle: Longevity and proportionality," in J. R. Carey and S. Tuljapurkar (eds.), Life Span: Evolutionary, Ecological, and Demographic 
Perspectives. Supplement to Population and Development Review, Vol. 29. Population Council, New York, pp. 183-207.

Leridon, H. 1977. Human Fertility: The Basic Components. Chicago: University of Chicago Press. 2004. "Can assisted reproduction technology compensate for the natural decline in fertility with age? A model assessment," Human Reproduction 19(7): 1549-1554.

- 2005. "A new estimate of permanent sterility by age: Sterility defined as the inability to conceive". Paper presented at the annual meeting of the Population Association of America, Philadelphia, PA, March 31-April 2, 2005.

Lesthaeghe, R. and D. van de Kaa. 1986. "Twee demografische transities?" in R. Lesthaeghe and D. van de Kaa (eds.), Bevolking: Groei en Krimp. Deventer: Van Loghum Slaterus, pp. 9-24.

Lesthaeghe, R. J. and L. Neidert. 2006. "The "second demographic transition" in the US: Spatial patterns and correlates". Unpublished working paper, University of Michigan.

Martin, J. A., B. E. Hamilton, S. J. Ventura, F. Menacker and M. M. Park. 2005. "Births: Final data for 2003," National Vital Statistics Reports 50(5).

Menken, J. 1985. “Age and fertility: How late can you wait?” Demography 22(4): 469-483.

Menken, J. and U. Larsen. 1986. "Fertility rates and aging," in L. Mastroianni and C. A. Paulsen (eds.), Aging, Reproduction and the Climactreric. New York: Plenum Press, pp. 147-166.

Menken, J., J. Trussell and U. Larsen. 1986. “Age and infertility,” Science 233(4771): 1389-1394. NCHS. 1997. Vital Statistics of the United States, 1997. Volume I, Natality. Final Release of Files. Atlanta Georgia: National Center for Health Statistics, Center for Disease Control. Available online at http://www.cdc.gov/nchs/datawh/statab/unpubd/natality/natab97.htm.

- 1999. Vital Statistics of the United States, 1999. Volume I, Natality. Atlanta Georgia: National Center for Health Statistics, Center for Disease Control. Available online at http://www.cdc.gov/nchs/datawh/statab/unpubd/natality/natab99.htm.

O’Connor, K. A., D. J. Holman and J. M. Wood. 1998. "Declining fecundity and ovarian ageing in natural fertility populations," Maturitas 30: 127-136.

Prioux, F. 2005. "Late fertility in Europe: Some comparative and historical data," Revue d'Épidémiologie et de Santé Publique_Epidemiology and Public Health 53(Hors-Série 2): 311.

Quesnel-Vallée, A. and P. S. Morgan. 2003. "Missing the target? Correspondence of fertility intentions and behavior in the U.S." Population Research and Policy Review 22(5-6): 557-574.

Rahman, O. and J. Menken. 1993. "Age at menopause and fecundity preceding menopause," in R. Gray, H. Leridon and A. Spira (eds.), Biomedical and Demographic Determinants of Reproduction. Oxford: Claredon Press, pp. 65-84.

Resolve. 2005. Preserving your fertility. Bethesda, MD: Resolve-The National Infertility Association. Available online at http://www.resolve.org.

Rizzi, E., A. Rosina and B. Colombo. 2005. "Age effect: Results from a detailed prospective study on daily fecundability," Revue d'Épidémiologie et de Santé Publique-Epidemiology and Public 
Health 53(Hors-Série 2): 57-63.

Settersten, R. A. and G. O. Hägestad. 1996. "What's the latest? Cultural age deadlines for family transitions," The Gerontologist 36(2): 178-188.

Skakkebæk, N. E., N. Jørgensen, K. M. Main, E. Rajpert-De Meyts, H. Leffers, A. M. Andersson, A. Juul, E. Carlsen, G. K. Mortensen, T. K. Jensen and J. Toppari. 2006. "Is human fecundity declining?" International Journal of Andrology 29(2): 2-11.

Slama, R., T. K. Jensen, T. Scheike, B. Ducot, A. Spira and N. Keiding. 2004. "How would a decline in sperm concentration over time influence the probability of pregnancy?" Epidemiology 15(4): 458-465.

Sobotka, T. 2004. Postponement of Childbearing in Europe. Amsterdam, The Netherlands: Dutch University Press, Population Studies Series.

Socialstyrelsen. 1998. "Förlossningar och barn födda efter provrörsbefruktningar 1982-1995". SoS-rapport 1998:7. Stockholm: Socialstyrelsen.

Spira, A., B. Ducot, M.-L. Guihard-Moscato, N. Job-Spira, M.-J. Mayaux, J. Ménétrier and J. Wattiaux. 1993. "Conception probability and pregnancy outcome in relation to age, cycle regularity and timing of intercourse," in R. Gray, H. Leridon and A. Spira (eds.), Biomedical and Demographic Determinants of Reproduction. Oxford: Claredon Press, pp. 271-284.

Stanford, J. L., P. Hartge, L. A. Brinton, R. N. Hoover and R. Brookmeyer. 1987. "Factors influencing the age at natural menopause," Journal of chronic diseases 40(11): 995-1002.

Statistics Sweden. 1999. Befolkningsutvecklingen under 250 år-Historisk statistik för Sverige. volume 2. Stockholm: Demografiska rapporter.

Swan, S. H. 2000. "The question of declining sperm density revisited: An analysis of 101 studies published 1934-1996," Environmental Health Perspectives 108(10): 961-966.

te Velde, E., M. Dorland and F. Broekmans. 1998. "Age at menopause as a marker of reproductive ageing," Maturitas 30: 119-125.

Thacker, P. D. 2004. "Biological clock ticks for men, too: Genetic defects linked to sperm of older fathers," Journal of the American Medical Association 291(14): 1683-1685.

Toulemon, L. 2005. "Who are the late mothers," Revue d'Épidémiologie et de Santé PubliqueEpidemiology and Public Health 53(Hors-Série 2): 13-24.

Toulemon, L. and H. Leridon. 1999. "La famille idéale: combien d'enfants, à quel âge?” INSEE Première 652: 1-4.

Trussel, J. and C. Wilson. 1985. "Sterility in a population with natural fertility," Population Studies 39(2): 269-286.

van de Kaa, D. J. 1987. "Europe's second demographic transition," Population Bulletin 42(1): $1-59$.

van Zonneveld, P., G. J. Scheffer, F. J. M. Broekmans and E. te Velde. 2001. "Hormones and reproductive aging," Maturitas 38(1): 83-91.

Vincent, P. 1950. "La stérilité physiologique des populations," Population 5(1): 45-54. 
Wallace, W. H. and T. W. Kelsey. 2004. "Ovarian reserve and reproductive age may be determined from measurement of ovarian volume by transvaginal sonography," Human Reproduction 19(7): $1612-1617$.

Weinstein, M., J. Wood and C. Ming-Cheng. 1993. "Age patterns of fecundability," in R. Gray, H. Leridon and A. Spira (eds.), Biomedical and Demographic Determinants of Reproduction. Oxford: Claredon Press, pp. 209-227.

Wilcox, A. J., C. R. Weinberg, J. F. O’Connor, D. D. Baird, J. Schatterer, R. Canfield, E. G. Armstrong and B. C. Nisula. 1988. "Incidence of early loss in pregnancy," New England Journal of Medicine 319: 189-194.

Wilmoth, J. R., L. J. Deegan, H. Lundström and S. Horiuchi. 2000. "Increase of maximum life-span in Sweden, 1861-1999," Science 289(5488): 2366-2368.

Wilmoth, J. R. and S. Horiuchi. 1999. "Rectangularization revisited: Variability of age at death within human populations," Demography 36(4): 475-495.

Wilmoth, J. R. and H. Lundström. 1996. "Extreme longevity in five countries," European Journal of Population 12(1): 63-93.

Ziadeh, S. and A. Yahaya. 2001. "Pregnancy outcome at age 40 and older," Archives of Gynecology and Obstetrics 27(1): 155-172. 